\title{
MINORIAS E TERRITÓRIOS: OCUPAÇÕES ${ }^{1}$
}

\author{
MINORITIES AND TERRITORIES: OCCUPATIONS
}

MINORÍAS Y TERRITORIOS: OCUPACIONES

Renata Lima Aspis

\section{RESUMO}

Este artigo tem principalmente a intenção de trazer alguns conceitos da filosofia, mais especificamente das chamadas filosofias da diferença, numa tentativa de pensar de outro modo, ou de buscar algum modo de pensar o acontecimento expresso no movimento das ocupações estudantis no Brasil, hoje. Inicialmente se coloca a necessidade de criar novas formas de pensar que escapem das velhas categorias de análise. Nessa primeira parte exploram-se os conceitos deleuzianos de imagem do pensamento e de acontecimento. Em seguida, o artigo trabalha o modo como Deleuze e Guattari pensam a criação de possíveis e as minorias, para chegar à tese de que as ocupações estudantis brasileiras na contemporaneidade são criação de territórios de re-existência, ou seja, ações de insistir na vida humana que cria sentido próprio.

PALAVRAS-CHAVE: Ocupações estudantis; filosofias da diferença; re-existência

\section{ABSTRACT}

This article has mainly the intention of bringing some philosophical concepts, specifically concepts from those philosophies called philosophies of the difference, for the attempt of thinking in another way, or searching some way of thinking the student's events of occupation, that take place in Brazil nowadays. To introduce, it puts the necessity of creating new ways of thinking, that scape from the old categories of analyses. In this first part explores the Deleuze's concepts of image of thought and event. Afterwards the article works with Deleuze and Guattari's way of thinking the creation of possibles and their concept of minority to reach its thesis that the Brazilian student's occupations in the contemporaneity are creation of territories of re-existence that means that they are about actions of insistence in human life, insistence in being as creation of its own sense.

KEYWORDS: Student's occupation; philosophies of difference; re- existence

\section{RESUMEN}

Este artículo tiene como objetivo principal presentar algunos conceptos de la filosofía, en específico aquéllos de las llamadas filosofías de la diferencia, en un intento de pensar las cosas de otra manera o de buscar alguna forma de pensar el acontecimiento expreso en el movimiento de las ocupaciones estudiantiles en Brasil, hoy. Se pone, inicialmente, la necesidad de crear nuevas formas de pensar que se diferencien de las viejas categorías de análisis. En esta primera parte, se exploran los conceptos deleuzianos sobre las imágenes del pensamiento y acontecimiento. Posteriormente, el artículo trata la forma de pensar de los filósofos Deleuze y

\footnotetext{
${ }^{1}$ Doutora em Educação - Universidade Estadual de Campinas (UNICAMP) - Professora de filosofia - Faculdade de Educação - Universidade Federal de Minas Gerais (UFMG) - Pampulha, Belo Horizonte, MG. Email: renaspis@terra.com.br
}

Submetido em: 02/12/2016 - Aceito em: 08/02/2017

C ETD- Educação Temática Digital Campinas, SP v.19 $\quad$ n.esp. $\quad$ p. 63-74 jan./mar. 2017


Guattari sobre la creación de posibles y de minorías para tener como tesis de que las ocupaciones estudiantiles brasileñas en la contemporaneidad son creación de territorios de re-existencia, es decir, son acciones de insistencia en la vida humana, que crea sentido propio.

PALABRAS CLAVES: Ocupaciones estudiantiles; filosofías de la diferencia; re- existencia

\section{OUTRAS FORMAS DE PENSAR}

Foucault (1995, p. 239) pensa que "[t]alvez, o mais evidente dos problemas filosóficos, seja a questão do tempo presente e daquilo que somos neste exato momento". Quais são as questões do tempo presente? O que somos neste exato momento? Difícil desenvolver essas antenas sensíveis para captar não só o que está acontecendo no momento, como perceber por onde é possível abrir frestas na criação de outros possíveis; teriam que ser antenas enormes, como as das baratas, que são maiores do que seus corpos. Talvez os dias atuais sejam difíceis de entender não apenas pela intensidade e pela alta velocidade em que as coisas se dão, mas principalmente porque as coisas são novas. Elas são difíceis de entender para aqueles que não são esses jovens estudantes ocupantes, aqueles que já têm forjadas algumas categorias de análise arraigadas, surradas pelo uso contínuo. É preciso ter cuidado, então, porque a tentativa de encaixar um acontecimento em sua novidade nas velhas categorias, forçando-o a caber nas fôrmas, cortando pedaços, distorcendo, apertar para caber, acaba por destruí-lo. Tentar identificar no acontecimento as relações que sempre se vê nas coisas, buscar detectar suas faltas e marcar essas ausências, acusar suas falhas, é perigoso. Pois quando não se consegue reconhecer o conhecido, reduz-se tudo ao já sabido, e isto mata, acaba com o vivo da vida. Não há novas categorias estão disponíveis para entender o que está se passando, mas pode-se tentar, pode-se e deseja-se tentar criar novas formas de pensar. Ser dissidente, como sugere Foucault (2008): usar "dissidência", inspirados pelo movimento intelectual de oposição ao sistema comunista, na união Soviética e nos países do bloco soviético, no início dos anos 1970, que no original em russo, inakomysliachtchie, quer dizer exatamente: "os que pensam de outra maneira". Porém é preciso atenção, pois não se trata de pensar outras coisas da mesma maneira, mas antes de pensar de outra maneira - dois movimentos muito distintos.

Deleuze e Guattari (1997) chamam atenção para o fato de que normalmente se critica os conteúdos de pensamento, as ideologias. No entanto, apontam a necessidade de verificar as formas de pensamento, mais do que seus conteúdos, de tentar fazer um estudo das imagens que recobrem todo o pensamento como uma forma a priori, uma fôrma, que

(C) ETD-Educação Temática Digital Campinas, SP v.19 n.esp. p. 63-74 jan./mar. 2017 
seria uma forma-Estado, desenvolvida no pensamento. ${ }^{2}$ Esse estudo seria aquilo que chamam de noologia (noos ou nous, em grego, é pensamento, intelecção, intuição, entendimento). Para os autores, há uma imagem do pensamento que o recobre inteiramente: "O pensamento já seria por si mesmo conforme a um modelo emprestado do aparelho de Estado, e que Ihe fixaria objetivos e caminhos, condutos, canais, órgãos, todo um organon [...] a forma-Estado desenvolvida no pensamento." (DELEUZE; GUATTARI, 1997, p. 43). Como devir inakomysliachtchie? Como tornar-se dissidente? Como criar saídas para a modulação-captura do aparelho de Estado: forma de pensar-Estado, forma de sentir-Estado, forma de agir-Estado, reprodução-Estado? Talvez se trate, como chamam atenção esses pensadores, de levar a sério o pensamento, isto é, dedicar-se a encontrar outras formas de pensar, pois "quanto menos as pessoas levarem a sério o pensamento, tanto mais pensarão conforme o que quer um Estado." (DELEUZE; GUATTARI, 1997, p. 47).

Trata-se, portanto, de escapar das velhas formas de pensar, sentir e desejar movidas pela lógica do capital, pelas exigências do mercado, pelo legado da tradição, pelo "normal", o habitual, pelos desejos midiaticamente produzidos, pelos apelos das novas tecnologias... pela preguiça e a covardia. Trata-se de um grande desafio, pois quantas vezes, ao lutar contra o machismo, não o fazemos de forma machista, por exemplo, ou ao lutar contra a opressão, não oprimimos mais ainda? Desviar disso, o pensar como Estado, por exemplo, entre outros tantos exemplos: legitimar a qualidade pela quantidade, acreditar na representatividade como forma de relação humana, aceitar a cisão entre o que se pensa e o que se faz como inevitável, aceitar a injustiça e a miséria como decorrentes de uma "natureza humana", acreditar na razão como instrumento máximo para solucionar os problemas da existência, postular o "ou", ou isto ou aquilo, acreditar em um mundo único, numa linearidade progressiva da vida, na natureza dos gêneros feminino e masculino, e patologizar todo o resto, acreditar no poder como uma força vertical contra a qual podemos resistir opondo força contrária, praticar monogamia como fidelidade, imaginar o amor materno como incondicional etc., amar o espírito de rebanho, enfim, "todo um consenso" que aprisiona a vida.

\footnotetext{
$2 \mathrm{O}$ estudo bastante detalhado sobre o conceito de 'imagem do pensamento', e originalmente ali criado, está em Diferença e repetição, obra de Deleuze de 1968, anterior ao seu encontro com Guattari. Nesta obra, ele estuda minuciosamente as imagens do pensamento de Platão, Descartes e Kant, para juntar elementos para fazer a defesa de um 'pensamento sem imagem', que poderia ser dito um pensamento-multiplicidade, um pensamento-rizoma, um pensamento da diferença em si.
}

(C) ETD-Educação Temática Digital Campinas, SP v.19 n.esp. p. 63-74 jan./mar. 2017 
Como diz Proust (2016, p. 25), "Talvez a imobilidade das coisas ao nosso redor thes seja imposta pela nossa certeza de que tais coisas são elas mesmas e não outras, pela imobilidade de nosso pensamento em relação a elas". Como então criar novas formas de pensar? Hoje, é urgente esse exercício, pois o que está se passando é novo e exige novas formas de pensar, novas formas de sentir e de perceber, novas formas de colocar os corpos em movimento. Como resistir? Trata-se de perguntar sobre as formas possíveis. Como criar possíveis? Trata-se de recusar as formas dadas, uma vez que estas já não servem. Para aquele que não quer distorcer os acontecimentos para que caibam nas suas velhas formas de pensar, como criar outras categorias? Categorias que não sejam a redução de todos os possíveis às identidades fixas, que não sejam a redução de todos os compossíveis a serem criados à lógica binária, excludente? Teriam que ser categorias móveis, também elas, teriam que ser temporárias, para acompanhar o movimento dos acontecimentos, e providas de órgãos sensoriais, antenas de baratas, com receptores de várias dimensões. Sim, essa, talvez, seja a tarefa mais urgente para os que querem pensar: encontrar novas formas, pois trata-se de pensar o acontecimento.

Trata-se, portanto, de libertar o pensamento de qualquer imagem, de qualquer forma a priori, de engendrar "um pensamento-acontecimento [...] em vez de um pensamento sujeito, um pensamento-problema no lugar de um pensamento-essência ou teorema, um pensamento que faz apelo a um povo em vez de se tomar por um ministério" (DELEUZE; GUATTARI, 1997, p. 48).

Importante aqui verificar, contudo, qual é a dificuldade em pensar o acontecimento.

Para Deleuze, o acontecimento tem duas dimensões: o da enunciação, feita por meio dos signos, e o da efetuação nos corpos, mediante a ação. O acontecimento deleuziano, formulado a partir da herança leibniziana, se expressa pelos agenciamentos coletivos de enunciação, criando os possíveis. No entanto, não se limita à enunciação, tem ainda de ser atualizado nos corpos, por meio dos agenciamentos maquínicos. Cada acontecimento é a criação de um possível que se enuncia por signos, e que deve se efetuar na ação. Tem-se que dizer, por conseguinte, que os possíveis, para Deleuze, têm de ser criados. Eles não existem para além daquilo que os expressa - o verbo, códigos, signos -, ou seja, não são transcendentes tampouco dados a priori, como na tradição platônica. Uma vez que não se trata da realização de algo já dado, eles têm de ser criados e depois atualizados, efetuados. Acontecimento: enunciação e efetuação de possíveis - criação. "[O] acontecimento é inseparavelmente o sentido das frases e o devir do mundo; é o que, do mundo, deixa-se envolver na linguagem e permite que funcione." (ZOURABICHVILI, 2004, p. 17), razão pela

CC ETD-Educação Temática Digital Campinas, SP v.19 n.esp. p. 63-74 jan./mar. 2017 
qual ele é produção de sentido e devir. Assim, o acontecimento, em primeiro lugar, produz uma transformação nas subjetividades, novas formas de sentir, pois não se suporta mais aquilo que até então era suportável. É abertura para novos mundos possíveis, pois apenas ele "nos faz ver aquilo que uma época tem de intolerável, mas faz também emergir novas possibilidades de vida" (LAZZARATO, 2006, p. 12).

Porém, o que temos vivido nessa civilização greco-romana, judaico-cristã, euroamericana, o que temos vivido aqui, desde a Modernidade, é um colossal abismo, ainda crescente, entre o que se diz e o que se faz. Entre o que se diz, o que se pensa, o que se prega, publica, reza, anuncia e enuncia e o modo como efetivamente se age. Tornou-se norma a ausência de correspondência necessária entre o que se fala e o que se faz. 0 homem moderno, ainda hoje, se orgulha de suas palavras, enaltece os discurso s e imagens que cria para representar a realidade, ao mesmo tempo em que se exime completamente da responsabilidade sobre o lugar onde seu corpo está, ocupa. Na poltrona ou na canga? $\mathrm{Na}$ sala de aula ou na cátedra?

O malogro em criar novos mundos, outros possíveis, muitas vezes, é dado pelo fato de a enunciação não passar de anunciação, o blá-blá-blá, a propaganda, a palavra de ordem, o assunto da semana que o 'público médio' tem de discutir. E a efetuação se restringe à reprodução, ao regurgitar do mundo pronto, o mundo-marketing. Todavia, como assinala Deleuze (1992, p. 179), "Criar não é comunicar mas resistir. Há um liame profundo entre os signos, o acontecimento, a vida, o vitalismo."

A dificuldade em pensar o acontecimento deve-se à opressão, ou seja, ao impedimento do movimento no pensamento, e "se as opressões são tão terríveis é porque impedem os movimentos" (DELEUZE, 1992, p.152). A captura pelo Estado no pensamento se dá na sua modulação; captura que já não se limita a uma modelagem, mas forja a ilusão de movimento, balizando os fluxos, determinando o campo de possíveis, governando o pensamento, de modo a fazê-lo corresponder aos desejos fabricados e vendidos, produzindo corpos obesos, cevados, consumistas e, ao mesmo tempo, anoréxicos, sempre em falta, desesperados na sua incompletude insaciável. Corpo que não age, não efetua.

(C) ETD-Educação Temática Digital Campinas, SP v.19 n.esp. p.63-74 jan./mar. 2017 


\section{MINORIAS}

No entanto, atenção: "[...] não há relação de poder sem resistência, sem escapatória ou fuga, sem inversão eventual" (FOUCAULT, 1995, p. 248).

Novas coisas estão acontecendo. A partir de 1999, com a "Batalha de Seattle", inaugura-se uma nova forma de ação política, direta; centenas de pequenos grupos, reunindo milhares de pessoas, vindas das mais diversas partes do planeta, grupos com pautas díspares, toda uma multiplicidade em uma só voz para defender a justiça social, o povo, a democracia, o direito de decidir sobre o que o mundo pode ser. A ação do qualquer um, milhões deles, com seus corpos atravessados, saindo às ruas para expressar seus desejos, no mundo todo - Primavera Árabe, Occupy Wall Street, Indignados na Espanha -, contra os desmandos da política representativa, contra os planos do mercado universal operados pelos Estados - planos de produção de miséria acima de tudo, miséria para um maior número de pessoas e riqueza para uma parte ínfima da população mundial. $E$ isto que se passou aqui, no Brasil, em 2013, e mais recentemente a ação dos secundaristas, as ocupações das escolas e universidades, o que é isso ${ }^{3}$ O que está acontecendo? É urgente a criação de novas formas de pensar, novas formas de sentir, de perceber, mover-se, desejar...

Em relação às ocupações estudantis, pode-se arriscar afirmar que o que está circulando por aí são outros desejos e outras formas de atualizá-los nos corpos, outras formas de agir com os outros, ou seja, outras éticas, na cidade, na polis, constituindo-se portanto em ações políticas. São corpos que escapam em outras estéticas. Esses seriam desejos não capturados pelo 'semiocapitalismo' (VIRTANEN, 2011). O capitalismo que atribui um sentido a tudo, usurpando dos possíveis humanos a sua humanidade, esta que se configura justamente na possibilidade de criar sentidos para a vida. O capitalismo, que já ultrapassou a produção de mercadorias e até mesmo a produção de mundos, agora já oferece sentidos para a vida; a existência humana já está resolvida antes mesmo de começar, sem problemas. Porém, ainda pode-se bradar: criar seus próprios valores e não apenas escolher entre alternativas previamente determinadas. Decidir! Com inspiração

\footnotetext{
3 Primeiramente esse movimento de ocupação aconteceu nas escolas secundaristas paulistas, contra o fechamento de quase cem escolas, no final de 2015. Posteriormente esse movimento se alastrou pelo país. $\mathrm{E}$ atualmente, no final de 2016, tanto nas escolas quanto nas universidades de todo brasileiras, a ocupações se posicionam contra Proposta de Emenda Constitucional que ameaça mortalmente o orçamento da União destinado à educação e à saúde, assim como contra Medida Provisória de reforma do Ensino Médio. Essas são imposições, sem consulta, sem discussão, de um governo desprovido de respaldo democrático.
}

(C) ETD-Educação Temática Digital Campinas, SP v.19 n.esp. p.63-74 jan./mar. 2017 
nietzschiana, pode-se afirmar que escolher não é decidir, escolher é obedecer aos limites do possível, é perambular dentro dos limites do campo predeterminado e suas alternativas dadas, passivo sob a lógica do 'ou', ou isto ou aquilo, pequeno mundo das não-contradições. Decidir, no entanto, é coisa bem distinta, é criar outros possíveis, escapar da condição de conduzido e fugir em direção ao imprevisível, ao fora.

O sentido da vida criado pelo semiocapitalismo é um só: ter dinheiro, comprar conforto, expor-se e buscar reconhecimento social, perseguir o prazer constante, a juventude eterna, o consumo infinito, a magreza, o cabelo liso... O aparelho de Estado, o grande aparelho de moer carne humana e biopoliticamente fabricar mais um tijolo do muro ${ }^{4}$, trabalha para produzir um sentido único para a vida, disfarçado em mil escolhas nas prateleiras, em constantemente renovados modelos para consumir. No entanto, o que se vê acontecer agora é o levante de uma minoria tratando de criar modos menores de viver, de inventar a vida, de criar a vida como uma obra de arte, sem pressupostos, sem a obrigação de continuidade em relação às lógicas estabelecidas, as religiões, as opiniões blábláblá da TV, 'teletela', das redes sociais, dos aparelhos eletrônicos de controle pessoal que apitam no bolso... É possível escapar aos modelos-fôrmas e criar novas formas.

O levante de uma minoria que é muita gente, numericamente maior do que qualquer outra categoria, pois minorias e maiorias não se distinguem pelo número, não dizem respeito à quantidade (DELEUZE, 1992). As minorias podem ser mais numerosas, as mulheres, os negros, o povo... Já a maioria pode ser muito menos numerosa, uma vez que ela se define pelo modelo ao qual se deve estar conforme, "por exemplo, o europeu médio adulto macho habitante das cidades" (DELEUZE, 1992, p. 214). As, minorias, por sua vez, não têm modelo, são processo, são movimento, devir. Sua potência vem daquilo que elas criam e que passa mais ou menos para o modelo, mas que não depende dele, não fixa, é criação constante. $O$ modo de pensar do Estado naturaliza a inferioridade daquele que escapa ao modelo, as mulheres, os negros, as crianças, os loucos, os LGBTs todos (os mil sexos), os pobres, os "pardos", o povo. Os levantes das minorias são movimentos de dizer "basta de engolir que essa é nossa essência", basta de acreditar que o máximo que se pode fazer é se esforçar para chegar o mais perto possível do modelo. Modelo único. Vida única nunca alcançada totalmente e que nunca será, pondo-nos sempre em dívida. E toda a energia dispendida nesse esforço equivocado de alcançar o modelo dessa maioria - masculino,

\footnotetext{
${ }^{4}$ Referência ao filme Pink Floyd The Wall, de Alan Parker, 1982, EUA.
}

(C) ETD-Educação Temática Digital Campinas, SP v.19 n.esp. p.63-74 jan./mar. 2017 
branco, classe média, estudado, cidadão cis hetero, no seu carrão -, toda essa energia em se branquear, em se europeizar, se machistizar, desgasta, nega e dá mais e mais poder ao modelo.

Voltando a Foucault (1995): talvez ainda mais importante do que descobrir o que somos, seja recusar o que somos, recusar essa individualidade que nos foi imposta há vários séculos. Promover novas formas de subjetividade.

E é isso que esses movimentos de ocupação, hoje, estão provocando: eles nos apontam o esgotamento do modelo, o esgotamento da aceitação em negar-se a si mesmo como possível humano que cria. Cria a própria vida, do modo como desejar e como puder, em movimento incessante. $O$ qualquer um faz isso, o 'ninguém', aquele que não permite que se fale em seu nome, aquele que não tem nome. Estudantes muito jovens se conectam em agenciamentos e efetivam as enunciações de novos modos de viver, novas formas de pensar, novas maneiras de posicionar seus corpos.

Isso é Nietzsche: o camelo, animal de carga, obediente, orgulhoso de sua carga, aguenta mais e mais, até que corre para o deserto, corre para o seu deserto e se transforma em leão, pois é necessário dizer não! No deserto, o leão se encontra com o seu senhor, o grande dragão prateado que tem em cada uma de suas escamas escrito: tu deves! Tu deves é o grande senhor desse camelo que se tornou leão e agora diz não. $O$ dragão diz: tudo já foi criado, tudo o que já foi criado está em mim e tu, tu deves, tu deves isso, deves aquilo: senta direito, menina, cala a boca, obedeça, comporte-se, conforme-se, não pergunte, corra. E o leão diz: não! O leão diz: eu quero! E no que ainda, ó, senhores, é necessário que o leão ainda se transforme? Em criança. O que a criança pode ainda mais do que o leão, ó, senhores? Criar, a criança é necessária para criar. A criança é roda que roda por si mesma, é eterno recomeçar... As três transmutações do espírito - assim falou Zaratustra.

De forma análoga a movimentos de resistência do século XIX, chamados de sabotagem, nos quais os operários das fábricas colocavam os tamancos (sabot) nas engrenagens das máquinas, os estudantes colocam seus corpos nos prédios das escolas. Ocupam. Correm para o seu deserto e dizem não. Dizem: eu quero.

(C) ETD-Educação Temática Digital Campinas, SP v.19 n.esp. p. 63-74 jan./mar. 2017 


\section{TERRITÓRIOS}

O território está ocupado pelo "povo por vir", está ocupado por aqueles que não fazem planilhas prévias no Excel, por aqueles que não leram Gramsci e, desavisadamente, tomam o lugar, vão lá e fazem. Está ocupado por aqueles que não vieram trazer a consciência crítica para ninguém, aqueles que, apesar da tenra idade, e, talvez por isso mesmo, têm a percepção clara do intolerável. 'Estudantes' são uma minoria, assim como são uma multiplicidade, os ocupados não são uma massa identitária, 'estudantes' são seres do fora, aquilo que ainda não foi criado.

Ocupação é território, não é terreno. O território é determinado pela presença do corpo. Isto é, o que faz o território, no caso dos animais, por exemplo, é o fato de o animal estar lá fisicamente e, com seu corpo, com seu fluidos, marcar uma área, delimitando-a como sua: seu território. Ele deambula por ali, circula, refaz suas marcas, ele está lá, está presente. No entanto, não há território sem um vetor de saída, pois, ao contrário dos terrenos, a delimitação do território não é limitante, e o território enquanto tal só se constitui se não aprisionar. Os territórios, portanto, têm limites não fixos, abertos. Os territórios são móveis, pois dizem respeito aos corpos.

Ocupar é questão, então, de onde se coloca o corpo. Onde você coloca seu corpo. $\mathrm{Na}$ sala ou na rua. Na aula ou na assembleia. Na praça ou em casa. Na dimensão física, não se pode estar em dois lugares ao mesmo tempo, assim como dois corpos não podem ocupar o mesmo espaço ao mesmo tempo. O corpo das aulas e o corpo das manifestações, o corpo do cotidiano acadêmico e o corpo dos tocadores de tambor chamando para a rua. É necessário que se decida. A criação de territórios é feita na imanência, no aqui e agora, sem maiores delongas: agir, posicionar-se.

Ocupar é criar território. Só é um território porque está ocupado com os corpos, e é vivo. Não é "terra improdutiva", não é propriedade cercada, não está parado, por isso ocupação não é invasão. Por isso não tem sentido clamar neoliberalmente pelo desgastado e equivocado 'direito de ir e vir'. É território porque é feito de gente, ocupando e inventando a vida, a vida que ainda está por vir, imprevisível, porque ainda não foi inventada. $\mathrm{O}$ qualquer um pode fazer isso. Isso é micropolítica. Política menor, política das minorias. É a criação de "linhas de fuga", pelas quais se escapa, inventando... novas subjetividades, novas formas de vida.

(C) ETD-Educação Temática Digital Campinas, SP v.19 n.esp. p.63-74 jan./mar. 2017 
Vale verificar essa ideia de 'criação de linhas de fuga'. Sabe-se que a intensa obra de Deleuze e Guattari, marcada pela crítica do capitalismo, configura-se como a criação de uma outra chave de análise, trata-se de uma outra constelação conceitual, outro modo de entender as relações aí implicadas. Deleuze (1992) afirma que ele e Guattari certamente permaneciam sendo marxistas, já que não acreditavam em uma filosofia política que não estivesse centrada em uma análise do capitalismo, e que muito interessa o que Marx trouxe: uma "análise do capitalismo como sistema imanente que não para de expandir seus próprios limites, reencontrando-os sempre numa escala ampliada" (DELEUZE, 1992, p. 212). No entanto, ele continua explicando, em Mil Platôs, Deleuze e Guattari indicam outras direções, ao considerarem que uma sociedade se define menos por suas contradições do que por suas linhas de fuga, mais pelas minorias do que pelas classes, e buscam um estatuto para as "máquinas de guerra", "que não seriam definidas de modo algum pela guerra, mas por uma certa maneira de ocupar, de preencher o espaço-tempo, ou de inventar novos espaços-tempos: os movimentos revolucionários [...], mas também os movimentos artísticos são máquinas de guerra" (DELEUZE, 1992, p. 212).

Talvez se possa aqui encontrar pistas para pensar de uma outra maneira as ocupações estudantis que tomam o Brasil neste momento. Ocupações são escapes, linhas de fuga, criação de outros modos de existir. Ocupações são 'máquinas de guerra' que não se opõem 'ao aparelho de Estado' frente a frente, termo a termo. Ocupações não resistem pela negação, têm vida própria, criam, criam outras formas. O que os estudantes estão ocupando não são os prédios das instituições educacionais, eles estão ocupando a educação, reinventando formas de fazer, outros currículos, outras relevâncias, outros interesses, outras formas de posicionar os corpos e fazer política. Não é desejo de "Revolução". Não é sonho de outro mundo, um outro mundo único, para colocar no lugar do deposto, para tomar o lugar do Estado, seguindo a lógica do 'ou isto ou aquilo'. Isentos das crenças no movimento dialético da luta de classes que impulsiona a história, os jovens vão lá e criam territórios de mundos por vir, conectando-se de maneiras imprevisíveis. Sem oposição termo a termo, é escapar e criar. Não desejam a revolução, porque são insurreição.

Surgo: levante, revolta. Insurgo: rebelar-se, levantar-se. Uma ação de independência [...] um levante é um momento que surge acima e além do Tempo, viola a 'lei' da História. Se o Estado É História, como declara ser, então o levante é o momento proibido, uma imperdoável negação da dialética - como dançar sobre um poste e escapar por uma fresta (BEY, 2004, p.15-16).

CC ETD-Educação Temática Digital Campinas, SP v.19 n.esp. p. 63-74 jan./mar. 2017 
Levantam-se, estão aqui. Ocupam. E seus desejos estão espalhados, criando novos espaços-tempos. Eles resistem, porque ocupar é resistir. No entanto, é necessário atentar para a ideia de que resistir não é negar o que existe, mas criar. A resistência não pode se dar em função da negação de algo, isto seria pouco para ela. Trata-se da insistência em existir, é afirmação da vida. Resistência que pode ser alegre e que, sim, é oposição aos mecanismos e dispositivos desse capitalismo que, reiteradamente, se lança contra cada um, suprimindo suas vidas. Mas essa oposição não é termo a termo, não se dá no mesmo plano, não quer instaurar um novo Estado; ela desvia e inventa novas formas. Resistência é criação, é movimento insistente de re-existir. A existência do humano é criação de sentido para a vida, "criação de valores", ao modo de Nietzsche. Se há uma coisa que é o humano é a busca de criação de sentido, muitas vezes difícil e sempre necessária. O sentido é o que faz possível a vida nos homens. A eventual ausência de sentido é doença, é morte. Dessa forma, entendese a necessidade de resistência como movimento incessante, criação insistente que se retoma a cada captura. A cada assalto à vida, a cada aprisionamento ensejado pelo semiocapitalismo, reiterar a luta pela criação de sentido próprio, sentido original, aquele cuja origem é cada um. Microscópica e insistentemente, resistir. Re-existência é acreditar no mundo, é criar mundos.

Acreditar no mundo é o que mais nos falta; nós perdemos completamente o
mundo, nos desapossaram dele. Acreditar no mundo significa principalmente
suscitar acontecimentos, mesmo pequenos, que escapem ao controle, ou
engendrar novos espaços-tempos, mesmo de superfície ou volume reduzidos [...] É
ao nível de cada tentativa que se avaliam a capacidade de resistência ou, ao
contrário, a submissão a um controle (DELEUZE, 1992, p. 218).

Em breve, com certeza, os estudantes sairão dos prédios das escolas e das universidades, eles desocuparão. Em grande festa sairão como entraram, os territórios criados não são permanentes. Eles poderão fazer um grande festival e sair, liberando os prédios. Já não importa, pois o possível criado foi efetuado nos corpos, novas formas de vida foram criadas, novas formas de se relacionar, novas sensibilidades, novas subjetividades que não toleram mais o que toleravam. Novos mundos foram instaurados, de forma que já não se pode mais viver como se vivia.

(C) ETD- Educação Temática Digital Campinas, SP v.19 n.esp. p. 63-74 jan./mar. 2017 


\section{REFERÊNCIAS}

BEY, Hakim. TAZ: Zona Autônoma Temporária. Tradução de Renato Rezende. 2. ed. São Paulo: Conrad, 2004. (Col. Baderna)

DELEUZE, Gilles. Conversações, 1972-1990. Tradução Peter Pál Pelbart. Rio de Janeiro: Ed. 34, 1992.

DELEUZE, Gilles; GUATTARI, Félix. Mil Platôs: capitalismo e esquizofrenia, v. 5. Tradução Peter Pál Pelbart e Janice Caiafa. São Paulo: Ed. 34, 1997.

FOUCAULT, Michel. O Sujeito e o Poder. In: DREYFUS, Hubert; RABINOV, Paul. Michel Foucault: uma trajetória filosófica. Para além do estruturalismo e da hermenêutica. Tradução Vera Porto Carrero. Rio de Janeiro: Forense Universitária, 1995.

FOUCAULT, Michel. Segurança, território, população. Curso no Collège de France (1977-1978). Tradução Eduardo Brandão. São Paulo: Martins Fontes, 2008.

LAZZARATO, Maurizio. As revoluções do capitalismo. Tradução Leonora Corsini. Rio de Janeiro: Civilização Brasileira, 2006.

PROUST, Marcel. Em busca do tempo perdido. No caminho de Swann. vol. 1. Tradução Fernando Py. 3. ed. Rio de Janeiro: Nova Fronteira, 2016.

VIRTANEN, Akseli. Posfácio. In: GUATTARI, Félix. Máquina Kafka / Kafkamachine. Ed. bilíngue. Tradução Peter Pál Pelbart. São Paulo: n-1, 2011.

ZOURABICHVILI, François. O vocabulário de Deleuze. Tradução André Telles. Rio de Janeiro: Relume Dumará, 2004.

\footnotetext{
${ }^{1}$ Revisão gramatical do texto por: Ana Godoy
}

(C) ETD-Educação Temática Digital Campinas, SP v.19 n.esp. p.63-74 jan./mar. 2017 